\title{
Digital Technologies for Evaluating Stochastic and Velocity Properties of Sensorimotor Response of Adolescents
}

\author{
Kamenskaya V.G.* Tomanov L.V. \\ Federal State Budgetary Educational Institution of Higher Education "Yelets State University named after I.A. Bunin, \\ Yelets, Russia \\ *Corresponding author. Email: Kamenskaya-v@mail.ru
}

\begin{abstract}
The article presents experimental materials on the use of digital technologies in the development of an expert system for assessing the features of the stochastic and speed properties of the sensorimotor response of adolescents who master educational programs of varying degrees of complexity. The computer program generated sensory fluxes with different stochastic structures, estimated the reaction time to visual and auditory stimuli, as well as the degree of correlation of reaction time values with each other. In the experiment, adolescents were presented with three speed tasks in which it was necessary to carry out the fastest motor responses to each stimulus of the flow, the experiment ended with a complex differentiating task, which required the participants in the experiment to urgently inhibit motor reactions to one of the visual stimuli. The study was conducted using an author's computer program, which is based on the concept of nonlinear dynamics of large interactive systems. The experiments involved students from two schools in St. Petersburg (the total number of samples was 50): an academic gymnasium with an enhanced physical and mathematical cycle and schools with a humanitarian direction in the educational program. It is shown that the stochastic organization of sensory fluxes, in which the physical characteristics of acoustic and visual stimuli are identical, determines the speed parameters of motor responses to stimuli in different ways, as well as the degree of connectedness of individual sensorimotor reactions among themselves in adolescents of two different schools. Students of the school with a physical and mathematical orientation in educational programs have shorter reactions to sound than to visual stimuli, are characterized by differentiated reactions to the degree of organization and complexity of sensory fluxes, which is associated with a higher non-verbal and general intelligence. In students of the humanitarian school, the nature of the sensorimotor response is significantly less mediated by the stochastic properties of sensory flows.
\end{abstract}

Keywords: digital technologies, stochastic dynamics, sensorimotor reactions of adolescents, various

educational programs

\section{SUBSTANTIATION OF RESEARCH}

The last decade is associated with a technological leap in the field of informatization of society and digitalization of the economy. These events are considered as absolutely positive, although the voices of researchers and economists already sound about the possible negative results of the current technological revolution $[3,4,6]$. In the report of the head of the laboratory of neuroscience and human behavior of Sberbank of the Russian Federation A.V. Kurpatov at the Federation Council 02/12/2020 [1] provides an analysis of modern foreign research, mainly of American origin, on the evidence of the negative impact of the widespread adoption of digital technologies in society. From the materials of the report, it follows that the expanded use of gadgets by the young generation leads to the debilitation of children and adolescents, a sharp decrease in their intellectual and creative resources, to the destruction of the most important neural systems of the brain, irreversibly affecting behavior and the psyche. This alarming information is confirmed in some scientific articles and reports [2,4]. Teenagers and children quickly master information technology and gadgets, using mostly figurative language and rarely resort to detailed speech utterances.

Our work performed on children and adolescents in 20002010 only partially corresponds to these negative facts and forecasts. It was stated that high school students are not able to work independently using even the simplest network tools [8] in cases where information is supplied to local networks using written texts. High school students often do not understand the meaning of the message and give inadequate verbal reactions. It can be assumed, based 
on these facts, that the verbal and conceptual intelligence of modern adolescents, indeed, tends to decrease.

The psychodiagnostics of non-verbal and general intelligence, however, does not confirm this trend, since a comparative analysis of the effectiveness of solving the $\mathrm{J}$. Raven test by children of the same age, examined in 2008 and in 2014, did not prove a decrease in intelligence, but rather increase. Moreover, verbal and conceptual intelligence in these same groups does not have unambiguous and reliable trends, which indicates the incomplete dynamics of this type of intelligence [7].

In other words, the question of a reliable decline in intellectual resources in the present tense does not have a definite answer; the problem should be studied using standardized tests in a wide age range. In connection with the study of the impact of abrupt changes in the environment on humans and their intellectual resources, the most important task is to develop adequate ways and methods of studying information processes on cognitive functions and processes [5]. The initial theoretical position should be related to the idea of the nature of information and its properties.

Information is the main subject of the study and implementation of digital technologies, therefore the phenomenon of informational interactions in both natural and artificial nature is significant and meaningful [9-11]. Many achievements in the development of artificial intelligence are the result of modeling the natural processes of the brain and psyche of humans and animals. Studies performed on the registration of neuron activity in animals emphasize the possibility of studying information processes and their description using the language of mathematics of nonlinear processes of large interactive systems (LSI), one of the central criteria of the optimum of which is the degree of fractality as a specific type of stochastic dynamics with self-similarity and scaling [9]. Physiological works of this kind, of course, are hardly possible on humans, therefore, all arguments about the fractality and randomness of processes as options of weakly deterministic chaos in human brain systems are extrapolation facts and concepts discussed and obtained in animal models. Therefore, an important task is to find ways to study the information characteristics of real systems of the human body and brain, whose functions can only partially be strictly mathematically modeled, as well as assess the degree of closeness of their properties to stochastic characteristics of mathematical objects.

In the practice of experimental work, specific statistical approaches are known that allow calculating the informational properties of system processes as measures of their complexity, orderliness, and diversity [5].

It is known that the fractal mode of activity of large complex systems is dynamically stable and has an optimum functioning, i.e., minimum costs with the most efficient operation of the system. The experimentally observed optimization of dynamic systems in the fractal mode is approximate [10], reflects the desire of real systems to ideal models that correspond to the theoretically described properties of fractals, one of which implies the self-similarity of their structure and dynamics at different scales of time and space.

It can be assumed that intelligence, as an evolutionarily formed system of mental functions, should be sensitive to dynamic processes that have a certain stochastic, including fractal structure. This means that intelligence is not only able to display and fix dynamically organized fractal structures, but also that its individual functions and manifestations can also exhibit fractal properties [9]. If this is so, then human reactions that arise in response to optimally organized ways of organizing sensory information should have certain stochastic features. For example, to be fast and accurate at the same time as compared with reactions to stimuli similar in physical characteristics, but not possessing stochastic dynamics, which is typical for perceiving simple visual stimuli.

The solution to this experimental problem can be based on a classical psychophysiological technique - a correlation between the results of intellectual tests and psychophysiological parameters characterizing the properties of large neural systems, for example, on the calculation of the Hurst index [5] of dynamic reactions such as sensorimotor responses that arise on the flow of sensory stimuli.

Based on the literature, it can be expected that the fractal and chaotic parameters of stimulus flows affect the speed characteristics of the sensorimotor reactions and the degree of their connectivity over time in adolescents with different levels of general and nonverbal intelligence. In connection with this assumption, it is necessary to experimentally test the possibility of forming the ability to reflect the stochastic properties of stimuli in the indicated response characteristics, including the Hurst index in a teenage sample of schools that differ in requirements for the intellectual development of students.

\section{METHODOLOGY}

This problem was solved using the author's computer program for reflexometric examination, developed by Kamenskaya V. G. Tomanov V.L. and Uritsky V.M. [Certificate of state registration of the computer program No. 2013613651 "Complex stochastic reflexometry" Time-test "dated April 11, 2013, database No. 2013621330 dated October 7, 2013]. A fundamental feature of this program is its block structure, which allows creating a series of sensory stimulus streams of visual and sound modality with a given time organization of interstimulus intervals: from rigid with a constant value of intervals between individual stimuli to chaotic, characterized by maximum uncertainty. The sensory stimuli in all tasks were the same: three different types of visual stimuli, circles of red, blue, and green, of equal probability of presentation and sound clicks. Therefore, all visual stimuli had a high frequency of occurrence (0.75), auditory - 0.25. The average values of interstimulus intervals in all series were the same and equal to $1.0 \mathrm{sec}$.

Two types of tasks were used in the experiment: three simple speed series (with rigid, fractal, and chaotic 
regimes of interstimulus intervals) and with the generation of fast motor responses after each stimulus; one complex one in which in the fractal series it was necessary to slow down the motor response to the red circle. At the same time, all other stimuli remained excititive. Thus, in the last series, adolescents, depending on the color of the visual stimulus (green and blue), either gave a quick response or slowed it down when a red stimulus appeared on the screen. An important additional characteristic in this task was the number of errors in the form of a speed response to the red inhibitory stimulus.

A reflexometric examination of 10th-grade students from two schools in St. Petersburg (an academic gymnasium in the physical and mathematical fields and a humanitarian gymnasium with intensive study of the English language) was accompanied by a diagnosis of the degree of development of general and nonverbal intelligence using the standardized test J. Raven. The significance of differences in individual groups was assessed using the Student t-test for related samples (BP for sensory stimuli) and the Mann-Whitney criterion for the number of errors and false starts and Hurst index values. The significance of differences in the effectiveness of the test by J. Raven in the experimental and control groups was evaluated using Student's t-test for independent samples.

\section{MAIN RESULTS}

The implementation of a computer reflexometric program by adolescents who master educational programs of varying degrees of difficulty varies significantly. The article presents the results summarizing the testing materials for students from an academic gymnasium (experimental group of 25 people) and a mass school with a humanitarian bias (control group of also 25 people).

The averaged indicators of the reaction time to all sensory stimuli (dt), as well as the reaction time to visual and auditory stimuli separately in high school students, depending on the degree of difficulty of the problem, significantly change in series with the different dynamic organization (see Tables 1 and 2). Obviously, the shortest time indicators are recorded in the case of rhythmic and fractal organization of interstimulus intervals at high values of the Hurst index. In adolescents of the experimental group, a fairly high average accuracy of motor actions in response to sensory stimuli and the maximum number of anticipatory stimulatory motor reactions, the so-called false starts, are recorded. The longest average BP values for sound and visual stimuli were found in the task of visual differentiation, in which subjects were required to slow down the motor reaction to one of the visual stimuli: a red circle. It was also established that in the situation of visual differentiation, the average response time to all sensory stimuli (dt) significantly increases and the Hurst index decreases (Table

Table 1 The average group performance of sensorimotor tasks by high school students of the experimental group

\begin{tabular}{|c|c|c|c|c|c|c|}
\hline $\begin{array}{c}\text { Series and } \\
\text { Tasks }\end{array}$ & dt & BP sound & BP light & H (-) & False start & Mistakes \\
\hline Regular simple & $\begin{array}{c}170 \pm \\
22\end{array}$ & $\begin{array}{c}125 \pm \\
40\end{array}$ & $\begin{array}{c}217 \pm \\
17\end{array}$ & $\begin{array}{c}0.69 \pm \\
0.02\end{array}$ & $\begin{array}{c}7 \pm \\
2\end{array}$ & 0 \\
\hline Fractal simple & $\begin{array}{c}153 \pm \\
13\end{array}$ & $\begin{array}{c}177 \pm \\
25\end{array}$ & $\begin{array}{c}360 \pm * * \\
8\end{array}$ & $\begin{array}{c}0.62 \pm * \\
0.02\end{array}$ & $\begin{array}{c}15 \pm * \\
2\end{array}$ & 0 \\
\hline Chaotic simple & $\begin{array}{c}188 \pm * \\
10\end{array}$ & $\begin{array}{c}238 \pm * * \\
21\end{array}$ & $\begin{array}{c}259 \pm * * \\
5\end{array}$ & $\begin{array}{c}0.53 \pm * \\
0.02\end{array}$ & $\begin{array}{c}10 \pm * \\
1\end{array}$ & 0 \\
\hline $\begin{array}{c}\text { Visual } \\
\text { differential }\end{array}$ & $\begin{array}{c}224 \pm^{*} \\
13\end{array}$ & $\begin{array}{c}305 \pm * * \\
34\end{array}$ & $\begin{array}{c}381 \pm * * \\
12\end{array}$ & $\begin{array}{c}0.53 \pm \\
0.03\end{array}$ & $\begin{array}{c}9 \pm \\
1\end{array}$ & $\begin{array}{c}7 \pm \\
1\end{array}$ \\
\hline
\end{tabular}

Notes: the table shows the arithmetic means with confidence intervals at $\mathrm{P}=0.05 . *$ - differences in the data indicated in the line are reliable with respect to the parameters in the line above at $\mathrm{P}=0.05$; ** - the differences are significant at $\mathrm{P}=0.01$. Central delay time is the difference between the dt values in the differentiation problem compared to the simple one with a fractal mode is $71 \mathrm{~ms}$ 
Table 2 The average group performance of sensorimotor tasks by high school students of the control group

\begin{tabular}{|c|c|c|c|c|c|c|}
\hline Series and Tasks & $\mathrm{dt}(\mathrm{ms})$ & BP sound & BP light & $\mathrm{H}(-)$ & False start & Mistakes \\
\hline Regular simple & $\begin{array}{c}138 \pm \\
49\end{array}$ & $\begin{array}{l}41 \pm \\
85\end{array}$ & $\begin{array}{c}202 \pm \\
17\end{array}$ & $\begin{array}{c}0.62 \pm \\
0.02\end{array}$ & $\begin{array}{c}11 \pm \\
3\end{array}$ & 0 \\
\hline Fractal simple & $\begin{array}{c}219 \pm * \\
30\end{array}$ & $\begin{array}{c}227 \pm * * \\
43\end{array}$ & $\begin{array}{c}245 \pm * * \\
9\end{array}$ & $\begin{array}{c}0.56 \pm * \\
0.03\end{array}$ & $\begin{array}{c}4 \pm^{*} \\
2\end{array}$ & 0 \\
\hline Chaotic simple & $\begin{array}{c}233 \pm \\
28\end{array}$ & $\begin{array}{c}281 \pm \\
35\end{array}$ & $\begin{array}{c}253 \pm \\
11\end{array}$ & $\begin{array}{c}0.58 \pm \\
0.03\end{array}$ & $\begin{array}{c}3 \pm \\
2\end{array}$ & 0 \\
\hline Visual differential & $\begin{array}{c}329 \pm * * \\
17\end{array}$ & $\begin{array}{c}460 \pm * * \\
33\end{array}$ & $\begin{array}{c}385 \pm * * \\
17\end{array}$ & $\begin{array}{c}0.52 \pm^{*} \\
0.02\end{array}$ & $\begin{array}{l}1 \pm \\
0.5\end{array}$ & $\begin{array}{c}7 \pm \\
4\end{array}$ \\
\hline
\end{tabular}

Notes are the same as in Table 1 . The central delay time is $110 \mathrm{~ms}$.

The indicator of dynamic connection (correlation) of motor reactions is the Hurst index in high school students of the control group is relatively high only in the case of rhythmic distribution of interstimulus intervals. In series with a fractal and chaotic flow structure, a significant decrease in the Hurst index was recorded. The group average BP values for visual and acoustic stimuli and the $\mathrm{dt}$ value in the control group significantly decrease already in the series with the fractal organization of interstimulus intervals. At the same time, the speed response parameters of students in the control group in the chaotic and fractal speed series have close values.

An analysis of the reaction time (BP) values given in Tables 1 and 2 for individual modalities allows us to see both common features and some differences between responses to acoustic and visual stimuli in adolescents studying in two types of schools. The reaction time for sound stimuli in most cases is significantly shorter than for visual stimuli. Exceptions are high school students in the control group. For these adolescents, BP for acoustic stimuli is longer than for visual ones in the case of a chaotic series and tasks for visual differentiations in which they are reliable. This fact may indicate a low plasticity of neural mechanisms of selective attention of students of the mass school.

Analysis of the materials of the reflexometric program as a whole shows the convincing effect of the methods of dynamically organizing interstimulus intervals on the indicators of sensorimotor reactions of high school students. The fastest sensorimotor reactions with a high correlation (Hurst index value) were found in rigid series, which is typical for the subjects of both groups. This may indicate the ability of adolescents to display in the values of the reaction time the presence of a rigid time structure in the case of a rhythmic series. The fractal mode implies certain dynamic relationships of a correlation nature during the entire stimulus series, which is also reflected in the large Hurst index as compared to a randomly organized series in high school students of an academic gymnasium. Both of these modes are accompanied by the shortest reaction times. In the chaotic mode, the values of both the integral indicators $\mathrm{dt}$ and $\mathrm{BP}$ for sound and light are significantly large. Moreover, the number of false starts in rhythmically and fractally organized series reaches a maximum in comparison with the task of differentiation and with the speed task with the chaotic structure of interstimulus intervals.

The subjects of the experimental group are students of an academic gymnasium who master a complicated program in the physical and mathematical cycle. In these adolescents, non-verbal and general intelligence is significantly better developed compared to their peers who do not master a complicated educational program: these ratios are $103 \pm 10$ control group, $134 \pm 5$ experimental group (significance level of differences $p=0.001$ ). In addition, an assessment of the verbal abilities of students of an academic gymnasium also showed their significant advantage over students of a school with a humanitarian 
direction, but these differences are not reliable at accepted levels of significance. They can be considered as certain trends. It can be expected that reliable and significant differences in the effectiveness of intellectual activity will be reflected in the organization of basic psychophysiological mechanisms, such as: speed and statistical properties of sensorimotor integration and, consequently, an involuntary level of main memory. Analysis of the results given in Tables 1 and 2, makes it possible to detect a fundamental difference in the organization of sensorimotor reactions of adolescents of two groups, depending on the type of dynamic structure of interstimulus intervals.

More differentiated reactions of students of the academic gymnasium to the temporal structure of sensory series were found. This is manifested, firstly, in the presence of a significantly larger number of false starts and a smaller Hurst index in fractal series compared to regular ones. Secondly, the fastest and most accurate motor reactions with the maximum Hurst index for these subjects were found in the case of rhythmic organization of stimuli. Thirdly, a decrease in the dynamic organization of the sensory flow in the "chaos" series as compared to the fractal one also finds expression in the temporal and stochastic indicators of sensorimotor reactions. A decrease in dynamic ordering in a chaotic series leads to a significant increase in the integral value of the reaction time (dt), as well as the average group values of BP for sound, a significant decrease in the Hurst index and a significant decrease in the number of leading reactions. Fourth, the most difficult task of selective retardation of reactions to the red stimulus is accompanied by a significant slowdown in the response time to the stimuli of both modalities.

Attention is drawn to the response time to sound, which is significantly shorter in the group than BP to light with a relatively short central delay time of $71 \mathrm{~ms}$. The central delay time is the result of subtracting the $\mathrm{dt}$ value in the fractal velocity from a similar value in the differentiating problem. In other words, the value of the central delay time reflects an increase in the time taken to process sensory stimuli in the task of selecting an answer and organizing alternative reactions: inhibition of a red stimulus and pressing a key in response to the appearance of other sensory stimuli. The resulting short central delay time reflects the high quality of neural activity in the associative zones of the prefrontal cortex, which are responsible not only for the analysis of sensory signals but also for the organization of motor reactions in response to them based on well-developed random access memory.

All this indicates that intellectually well-off teenagers who train their thinking in the process of mastering a difficult educational program are characterized on an unconscious level by differential mechanisms of reflection of subtle dynamic differences in the structure of sensory flows, which is possible, perhaps, with the help of special dynamic properties of selective attention and main memory.

Students mastering educational programs with a large volume of humanitarian disciplines, as the results of our studies have shown, are characterized by a significantly lower level of development of non-verbal and general intelligence. These adolescents noted a different specificity of performing a reflexometric test. The most characteristic feature inherent in these subjects is the absence of any significant differences between the parameters of the fractal and chaotic series. As can be seen from the materials of Table 2, the results of these two series, which differ in the degree of ordering, have no significant differences. The parameters of sensorimotor reactions in a fractally organized series significantly differ from the parameters of sensorimotor reactions that arise in the case of a rigid rhythmic structure of the flow, which combines them with intellectually advanced high school students.

Performing inhibitory reactions by students with a humanitarian orientation in education leads to a significant increase in the time spent on sensorimotor integration with a significant decrease in the Hurst index. The last task is also accompanied by significantly longer sensorimotor responses to a sound stimulus, which confirms the conclusion about relatively less perfect mechanisms for switching selective attention in this most difficult series and reducing neural plasticity. In the subjects of the control group, the time of the central delay was significantly longer compared to the same indicator of the subjects of the experimental group, equal to $110 \mathrm{~ms}$. All this, on the whole, testifies to less perfect and mature mechanisms of reflection of the temporal structure of sensory flows, as well as less developed RAM, as well as more inertial mechanisms of sensorimotor integration and selective attention compared to adolescents in an academic gymnasium.

\section{CONCLUSIONS}

- The stochastic organization of sensory flows, in which the physical characteristics of acoustic and visual stimuli are identical, determines the speed parameters of motor responses to stimuli, as well as the degree of connectedness of individual sensorimotor reactions among students who master a complex educational program and have a high general and nonverbal intelligence.

- In adolescents from an academic gymnasium, the average values of BP for light stimuli are significantly higher compared to BP for sound in all series, which indicates differential reactions to sound and visual stimuli. These students are characterized by a decrease in the speed and stochastic properties of the sensorimotor response to the flow of stimuli having a chaotic dynamic mode.

- Students in the control group, intensively mastering the humanitarian disciplines, are characterized by a relatively lower sensitivity to the stochastic properties of sensory flows. In addition, these subjects have reduced the ability to carry out differentiated reactions to different stimuli compared to students in an academic gymnasium.

- The introduction into the task of the need to inhibit the motor reaction to one of the visual stimuli leads to a significant and reliable increase in the average BP for all 
sensory stimuli and to a decrease in the degree of connectedness of individual motor responses to each other in both groups compared to a simple fractal series.

- The ability of differentiated response to stimuli of sound and visual modality, as well as to the dynamic organization of sensory flows is associated with the high non-verbal and general intelligence of students, which develops in the process of mastering the educational disciplines of the physical and mathematical cycle.

\section{REFERENCES}

[1] A.V. Kurpatov, https: Ilyoutubelbk3fT7qogWM.

[2] T.A. Nestik, Sotsial'no-psikhologicheskiye aspekty otnosheniya cheloveka $\mathrm{k}$ novym tekhnologiyam, Aktual'nyye problemy psikhologii truda, inzhenernoy psikhologii i ergonomiki. Vypusk 8, Izd-vo «Institut psikhologii RAN», 2018, pp. 50-73

[3] E. Fayola, Chelovek dopolnennyy: stanovleniye kibersoznaniya, Voprosy filosofii, 3(2016) 147-162.

[4] D. Bavelier, Brains on video games, Nature Reviews Neuroscience, vol. 12 (2011) 763-768.

[5] S. Guastello, M. Koopmans, D. Pincus, Chaos and Complexity in Psychology, The Theory of Nonlinear Dynamic Systems. N.Y., London, 2009, 527 p.

[6] D.A. Gentile, Video game playing, attention problems, and impulsiveness: evidence of bidirectional causality, Psychology of Popular Media Culture, 1(2012) 62-70.

[7] V.G. Kamenskaya, L.V. Tomanov, Informatization of Society and intellectual development of children senior preschool age, Advances Business and Management Research, vol. 81(2019) 775-779. https://creativecommons.org/licenses/by-nc/4.0

[8] V.G. Kamenskaya, L.V. Tomanov, Computer network approaches in the occupation guidance of modern teenages, Advances in Economics, Business and Management Research, vol.105 (2020) 623-626

[9] C.T. Kello, G.G. Anderson, J.G. Holden, G.C. Van Orden, The pervasiveness of $1 / \mathrm{f}$ scaling in speech reflects the metastable basis of cognition, Cognitive Science, v. $32-7$ (2008) 1217-1231

[10] D. Stephen, J. A. G Dixon, Strong anticipation: Multifractal cascade dynamics modulate scaling in synchronization behaviors, Chaos solitons and Fractals, vol 44-1, issue: 1-3 (2011) 160-168
[11] S. Yasue, K. Munakata, M.Kato, S. Mori, Calculation of power law index for time series by means of its fractal dimention, Fractals, vol.4 (1996) 123-131 